\title{
Cracking Failure Analysis of T-type Welded Tee in Waste Heat Boiler
}

\author{
Qing-Ren WANG ${ }^{1}$, Zhen $\mathrm{CHEN}^{2} \mathrm{a}^{*}$, Xue-Qing $\mathrm{LIU}^{2}$, Kui WANG ${ }^{2}$, \\ Lu-Yi LU',b
}

\author{
${ }^{1}$ Guangdong Huizhou LNG Power CO., LTD, HuiZhou, Guangdong Province, China \\ ${ }^{2}$ School of Energy and Power Engineering, Huazhong University of Science and Technology, \\ Wuhan, Hubei Province, China \\ azhen_hust2015@163.com, ’hust_lly@hust.edu.cn \\ ${ }^{*}$ Corresponding author
}

Keywords: T-type welded tee, fracture mechanics, stress intensity factor, finite element analysis.

\begin{abstract}
In order to solve the crack problem of T-shaped welded tee in waste heat boiler of a LNG power plant, this paper proposed using the principle of fracture mechanics to analyze propagating crack quantitatively. Firstly, the stress distribution of T-shape welded pipe without structure default was analyzed. Based on the results of the analysis, the intensity factors of T-type welded pipe with different feature(such as location, length, depth, and so on) were calculated. The results show that both the length and the depth of the crack affect the stress intensity factor value. The surface crack is more dangerous than the buried depth crack. It was difficult to get stress intensity factor of the Ttype welded pipe in engineering .The results discussed in this paper are of great significance not only for the maintenance of pipelines, but also for other engineering.
\end{abstract}

\section{Introduction}

A lot of T-type welded tee were used in the waste heat boiler of a LNG power plant. The T-type welded joint leakage occurs frequently because the boiler tube works in high temperature, high pressure, corrosion and other harsh environments. It impacts on the economy and safety of plant operation incessantly. The T-type welded joint would inevitably have some defects in the manufacturing process, such as porosity, inclusions and so on. Analysis shows that cracking was always formed and developed by the defects under alternating thermal stress, which caused by the temperature variation in the T-type welded joint. These cracks are generated in the longitudinal or circumferential direction of the pipe, and a great degree of stress intensity is appeared in the crack zone, leading to crack failure. Therefore, it is important to evaluate the residual life of the cracked pipe and to detect the shape of the crack when a crack occurs in the pipe weld.

For the existence of semi-elliptical crack pipe, the majority of scholars have adopted the basic theory of fracture mechanics and finite element analysis method for solving. The general solution of the object is the stress intensity factor and $\mathrm{J}$ integral. Chun qing $\mathrm{Li}[1]$ proposed a combined Jintegral and finite element method to determine the stress intensity factor of inclined outer surface cracks in pressurized pipelines and proposed a special meshing method to simulate the crack region, and gave the influence factor of stress intensity factor ,The results show that the influence coefficient of stress intensity factor KI and equivalent stress intensity factor decrease with the increase of inclination angle while the influence coefficient of KII and KIII reach the maximum when the inclination angle is $45^{\circ}$. A Zareei [2]calculated the stress intensity factor at the deepest point of the semi-elliptic crack and proposed the weighting function of the high aspect ratio semielliptical crack on the basis of the finite element analysis to evaluate the stress intensity factor. Based on the finite element data and literature data, The weighting function is used to verify the stress field of crack surface and weld. Coules HE[3] used the weight function method to determine the effect of residual stress on the crack or structural stress intensity factor KI. This can be used to analyze only the structures containing defects or residual stresses, and demonstrate by examples. Sahu MK[4] conducted a study of three straight ducts with a circumferential crack or surface crack in a primary heat transfer system of a pressurized heavy water reactor in India and conducted 
fracture tests on these pipes. By means of tests and finite element analysis, The crack at the tip of the surface crack tube has a relatively low constraint and therefore has a higher JR curve. Jianliang $\mathrm{Yu}[5]$, Feng Ju[6], Chong Chen[7], Jie Song[8] and other scholars have used the fracture mechanics theory and the finite element analysis technique to calculate the stress intensity factor or J-integral of the stress field and crack zone of the T-type pipe, and also concluded that the use of stress intensity factors and J-integral to measure crack parameters is reliable.

In this paper, the stress intensity factor (KI) at the connection of T-type welded pipe is calculated and compared under internal pressure. Due to ANSYS workbench15.0 modeling comes with insert crack function, three-dimensional finite element T-duct model is divided into meshes and elliptic crack is established based on ANSYS workbench15.0. The stress intensity factors of different lengths and depth crack were calculated and analyzed, and the crack at different positions was also compared.

\section{Geometric modeling and meshing}

The object of present study is a power plant waste heat boiler T-type steam-water pipeline. due to the geometric shape is not continuous, the intersection of the corner of T-type pipeline structure often forms a large concentration of stress ,leading to even the pipeline under normal operating conditions, where the stress may reach the yield state. For this reason, in order to make the model calculation result closer to the real situation, the model of the solid T-pipe is simplified and also takes into account the T-type pipeline at the junction of the intersection line containing the weld situation. Taking into account the symmetry of the model, only the 1/4 T-pipe model is calculated, the basic parameters shown in Table 1. Although the industrial pipeline generally uses the shell element, but this kind of unit cannot reflect the primary stress and the secondary stress well, therefore it was used the linear elastic unit Solid45 unit to carry on the simulation. Hexahedral and tetrahedral meshes are commonly used cell grids, and hexahedral mesh quality is better. Therefore, a hexahedral mesh was used for the crack-free model, tetrahedral meshes was used for the crack model because it was hard to divide into hexahedral meshes. Weld is the main research area, so the location of the weld in the grid is relatively dense. The T-type welded pipe model and meshing are shown in Fig 1.

Tab. 1 Basic parameters of $\mathrm{T}$ - type welded pipe

\begin{tabular}{cccccc}
\hline Parameter & $\mathrm{R} 1(\mathrm{~mm})$ & $\mathrm{R} 2(\mathrm{~mm})$ & $\mathrm{T}(\mathrm{mm})$ & $\mathrm{Ex}(\mathrm{Pa})$ & Poisson's ratio \\
\hline Value & 32 & 22 & 6 & $2 \mathrm{X} 10^{11}$ & 0.3 \\
\hline
\end{tabular}

After the model is established and the mesh is divided, the pressure is applied to the inner wall of the pipe. The pressure load is $\mathrm{P}=0.1 \mathrm{MPa}$, and the symmetry constraint is imposed on the symmetry of the model. When the inner wall of the pipeline is compressed, two sides of the pipe are also subject to pressure, as a consequence, the pressure on both sides of the main pipe and branch is equivalent to:

Main pipe:

$$
P_{1}=-\left(P * R_{1}^{2}\right) /\left(\left(R_{1}+T\right)^{2}-R_{1}^{2}\right)
$$

Branch pipe:

$$
P_{2}=-P * R_{2}^{2} /\left(\left(R_{2}+T\right)^{2}-R_{2}^{2}\right)
$$



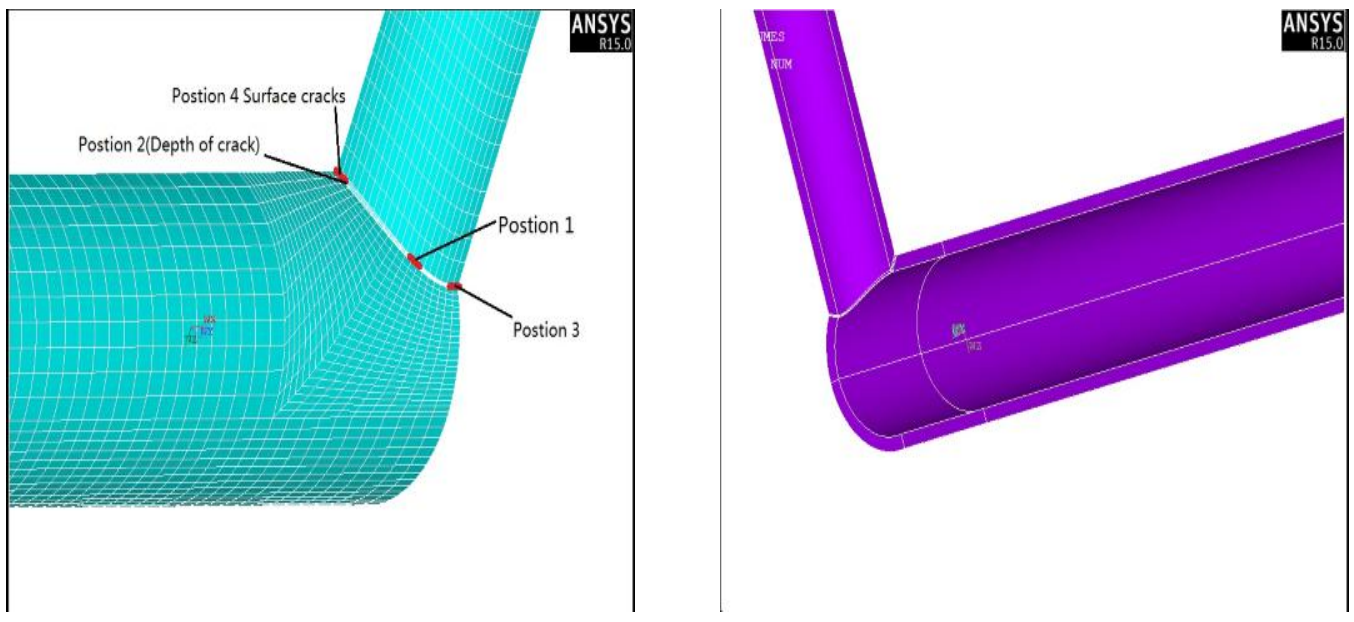

Fig. $1 \mathrm{~T}$ - type welded pipe model and mesh.

\section{Stress intensity factor at the joint of $\mathbf{T}$-shape welded pipes}

The stress singularity exists in front of the crack, and its influence on the crack field is approximately proportional to $1 / \mathrm{r}^{0.5}$ ( $\mathrm{r}$ is the distance from the crack fronts). The stress intensity factor is introduced in order to quantify the stress singularity, Its value is a function of applied load and crack geometry. There are three basic crack forms, that is to say, open type (mode I), in-plane shear type (mode II) and anti-plane shear type (mode III)[9]. When the applied load is perpendicular to the crack plane, The deformation of the crack body is confined to the open type (mode I). Mode I crack is the most common form, this paper only discusses on I- type crack appears at the weld on Tshape welded pipes.

We assume that the crack is semi-elliptical, the crack depth is $a \mathrm{~mm}$, and the half length is $b \mathrm{~mm}$. Since the maximum value of Von misses stress is found in the re-weld, it is assumed that the crack appears at the weld or near the weld. By means of ANSYS workbench 15.0, we discuss the length and depth of crack and the stress intensity factors at different places where crack appears.

Stress Distribution of T-shape Pipes with no Crack. The stress distribution of T-shape pipes under internal pressure is of great referential significance to the following simulation of crack propagation in pipes. Because the stress state is very complex inside and outside the wall of the $\mathrm{T}-$ shape on each point, we take the fourth strength theory-Von misses stress to represent it The results are shown in figure 2 .
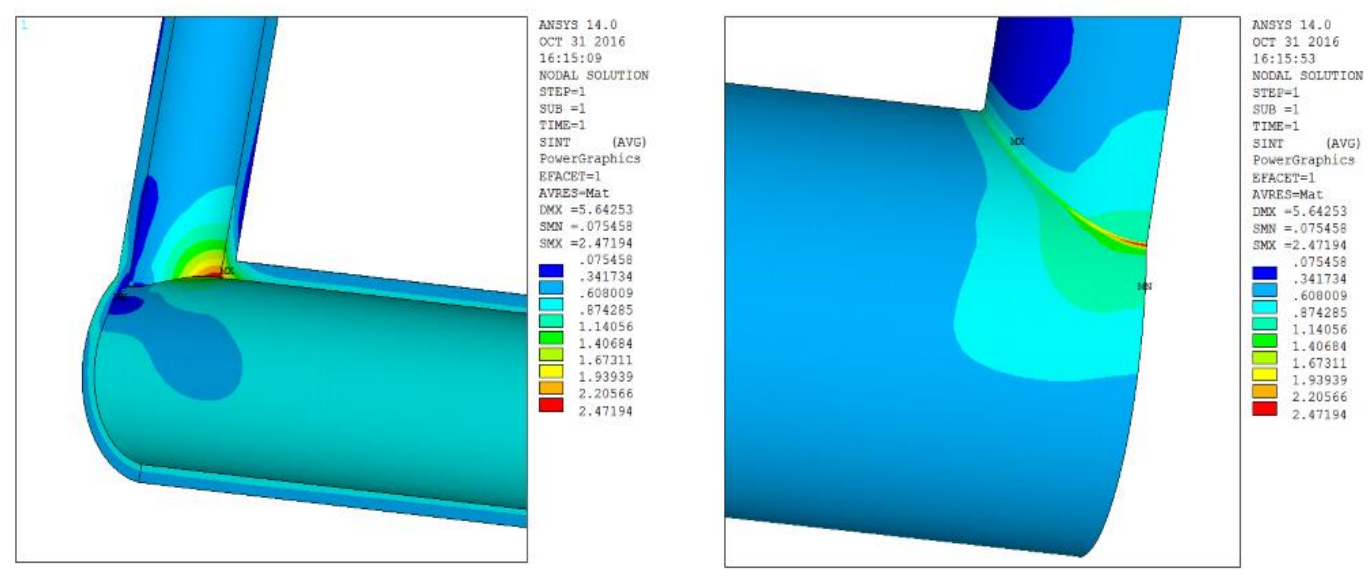

Fig. 2 Stress distribution of T-shape pipes with no $\operatorname{crack}(106 \mathrm{~N} / \mathrm{m} 2)$.

From fig. 2 we can learn that: (1) The stress of the T-type welded pipe has a great fluctuation inside and outside the wall at the joint of the main and branch pipes, furthermore, The stress of Ttype welded pipe in the shoulder and abdominal are local maximum, so these locations can be 
regarded as stress-dangerous location. Meanwhile the stress of Von misses on the shoulder surface of the inner wall is larger than that on the outer wall. According to the calculation, the maximum Von misses stress is 7.4 times the stress of the Von misses when the main pipes are away from the weld. (2)The Von misses stress varies from each other at the points of the T-shape welded pipe, the stress of the Von misses is very small and distributed evenly at the distance from the weld, and the maximum value of the stress appears near the weld with large fluctuations, so larger crack easily appears near the weld and close to the weld.

Stress Intensity Factor When Crack Size Changes. One semi-elliptical crack anywhere was set up in the T-type welded pipe near the weld for simulation of the general crack, as shown in Figure 1(Position 1). When the internal pressure was $0.1 \mathrm{MPa}$, we studied the effects of both the crack length and depth variations on the cracks. When the crack depth is $4 \mathrm{~mm}$, the stress intensity factor was calculated with half length of the crack changed from $1 \mathrm{~mm}$ to $4 \mathrm{~mm}$. It can be seen from the left graph of Fig. 3 that the maximum stress intensity factor appeared at both ends of the semi-elliptical crack tip when the crack depth was constant, and the maximum stress intensity factor increased as the crack length increased. Meanwhile, when the internal pressure was $0.1 \mathrm{MPa}$ and half length of the crack was constantly $3 \mathrm{~mm}$, the stress intensity factor was calculated with the crack depth changed from $1 \mathrm{~mm}$ to $4 \mathrm{~mm}$. As can be seen from the right graph of Figure 3, the maximum stress intensity factor was also found at the two ends of the semi elliptical crack tip and increased with the increase of the crack depth.

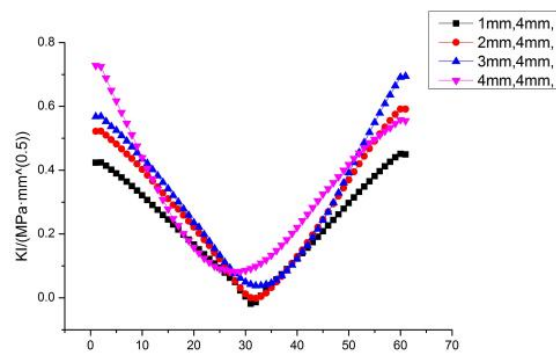

The same depth, different length of the crack block

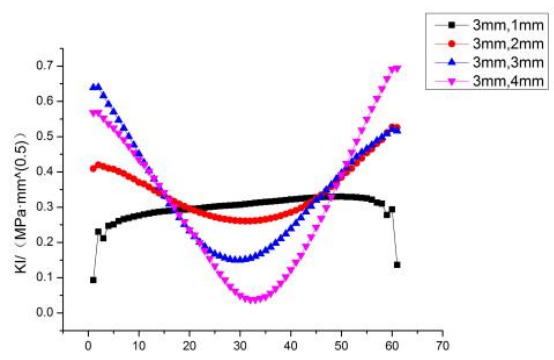

Different depths, the same length of the crack block

Fig. 3 Crack Stress intensity factor at different length and different depth(MPa·mm1/2).

The Stress Intensity Factor of Different Location. For the T-type welded pipe junction, there existed local stress maximum due to the stress value of a large fluctuation. The comparison of the stress intensity factors in the crack zone at different welds will help to determine the maximum dangerous location for T-type welded pipes. The four position were any position at the intersection (position 1), the shoulder of the main pipe (position 2), the main pipe belly (position 3) and main pipe shoulder surface (position 4), as shown in Figure 1. Fig. 4 showed the stress intensity factor of the above four different positions when the internal pressure is $1 \mathrm{MPa}$. For the crack region at position 1, the stress intensity factor value was very small and the value at the crack tip was almost zero; for the cracked region at position 2, the stress intensity factor was generally larger near the outer weld. However, for the shoulder of the main pipe, the Von misses stress value of the inner wall surface was greater than the Von misses stress value of the outer wall surface. For the cracked region at position 3 , the position 3 was located at the center of the main tube abdomen. There also existed a local maximum of the Von misses stress. It can be seen from Fig. 4 that the maximum stress intensity of crack zone in position 3 was much larger than that of other locations, and that the stress intensity factor of crack zone in position 3 at the two sides of the crack tip was larger, while at the middle was small. There also existed a local Von misses stress maximum for the cracked region at position 4, which is located on the outer wall of the shoulder of the main tube, but here the maximum stress is smaller than that of the above other three positions, where the stress intensity factor was also relatively larger, but the value is smaller than that of the position 3 . In contrast to the maximum stress intensity factors at locations 2,3 and 4, it can be concluded that the maximum value of local Von misses stress is probably located at the maximum position of stress intensity factor, that was, the dangerous point. The surface crack had a greater stress intensity factor than the 
depth of the crack, which indicated that the surface crack was more dangerous than the depth of the crack.

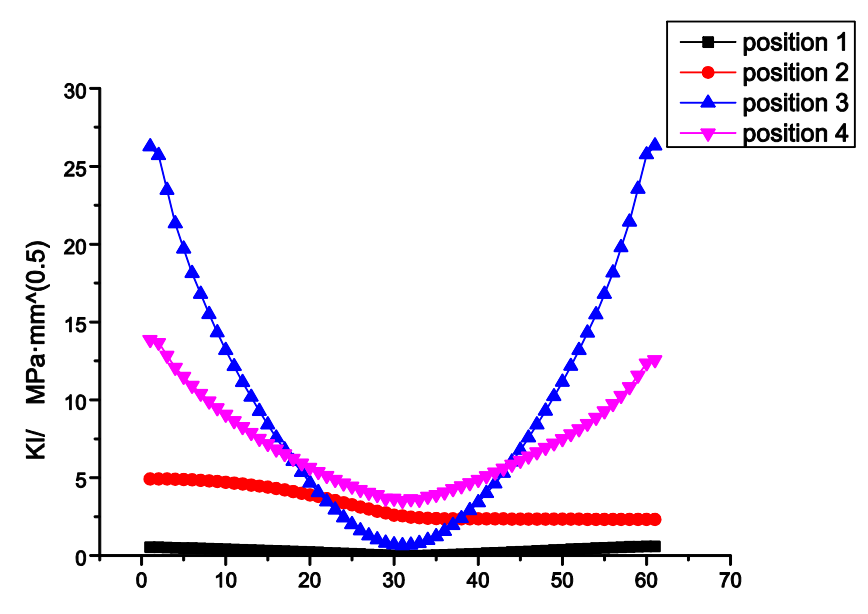

Fig. 4 Stress Intensity Factors of Cracks When Crack Location Changes(MPa mm1/2).

\section{Conclusion}

Based on simulation platform of ANSYS APDL and workbench, the T-type welded pipe without cracks and cracks in the case of numerical simulation. This paper mainly investigates the variation of Von misses stress in crack-free T-type welded pipe, and under the results, we can assume that the crack exists in these areas and calculate the stress intensity factor. The results show that the stress intensity factor is greater at the local maximum Von mises stress, which was dangerous areas on the pipeline, and the surface crack is more dangerous than the buried depth crack. The depth and length will affect the value of the stress intensity factor of crack, indicating that the crack propagation to a certain stage will be the development of material failure and affect the normal operation of the pipeline. These results was difficult to find in the general stress intensity factor manual, which is very important for the maintenance of the power plant, and it can also provide some reference for other engineering.

\section{References}

[1] Li C-Q, Fu G, Yang W. Stress intensity factors for inclined external surface cracks in pressurised pipes[J]. Engineering Fracture Mechanics. 2016,165:72-86.

[2] Zareei A, Nabavi SM. Calculation of stress intensity factors for circumferential semielliptical cracks with high aspect ratio in pipes[J]. International Journal of Pressure Vessels and Piping. 2016,146:32-38.

[3] Coules HE, Smith DJ. The maximum possible stress intensity factor for a crack in an unknown residual stress field[J]. International Journal of Pressure Vessels and Piping. 2015,134:3345.

[4] Sahu MK, Chattopadhyay J, Dutta BK. Fracture studies of straight pipes subjected to internal pressure and bending moment[J]. International Journal of Pressure Vessels and Piping. 2015,134:56-71.

[5] Jianliang Y, Chuanping Y, Tuo W, et al. Stress Intensity Factor Analysis of Elliptical Cracks in Three - way Inner Corners [J]. Pipeline Technology and Equipment. 2014(05):1-3+10.

[6] Feng J, Hehui W,Pengxiang J , et al. Stress intensity factor of three-tube pipe containing axial penetration by Finite element analysis [J]. Chemical Technology ,2014,05:36-41. 
[7] Chong C. Cause Analysis of Weld Cracks in Tee of Supercritical [J]. Quality and Technical Supervision Research. 2015(06):17-19+39.

[8] Jie S, Zuowen W,Xiaoping Meng. Stress Intensity Factors of Pressure Piping Containing Defects under Thermal - Stress Coupling Field [J]. Forest Engineering. 2010(03):33-36+65.

[9] Yizhong L. Engineering fracture mechanics [M]. Xi'an Jiaotong University Press,2006. 